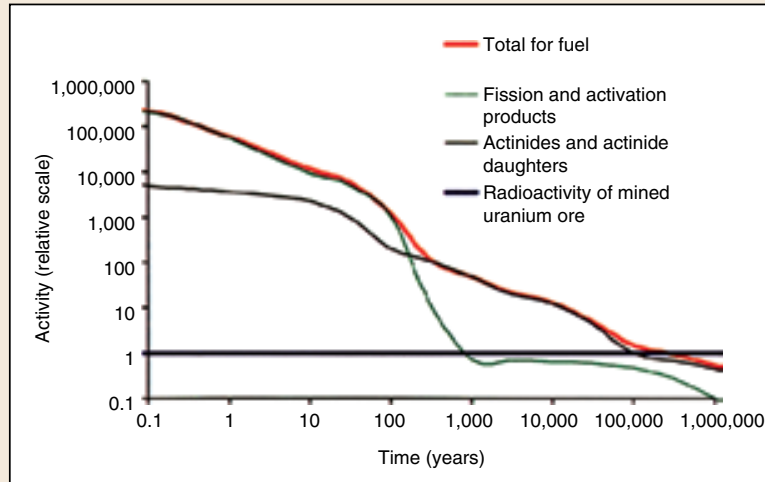

Figure 2. Relative radioactivity of spent nuclear fuel with a burnup of $38 \mathrm{MWd} / \mathrm{kgU}$. The activity is dominated by fission products during the first 100 years, thereafter by actinides. ${ }^{11}$

and requirements for the development of a geologic repository were outlined by the Nuclear Waste Policy Act of 1982. Worldwide, there are active programs of research and site investigations in a wide variety of rock types - clay in Belgium, salt in Germany, granite in Sweden and Finland, and volcanic tuff in Russia and the United States. However, to date, there is no geologic repository in operation that is receiving spent nuclear fuel or high-level nuclear waste. The challenge has not only been one of "politics," the development of regulations, and social acceptance, but also one of developing a strong scientific basis for the prediction of materials properties and repository performance over hundreds of thousands of years. ${ }^{12,13}$

\section{References}

1. R.L. Garwin, Interdiscip. Sci. Rev. 26, 265 (2001).

2. L.J. Carter, Nuclear Imperatives and Public Trust (Resources for the Future, Inc., Washington, DC, 1987).

3. E.N. von Hippel, Science 293, 2397 (2001)

4. W. Lutze, R.C. Ewing, Radioactive Waste Forms for the Future (NorthHolland, Amsterdam, 1988)

5. R.C. Ewing, Ed., Elements 2, 331 (2006)

6. R.C. Ewing, Prog. Nucl. Energy, 49, 635 (2007).

7. R.C. Ewing, W.J. Weber, J. Lian, J. Appl. Phys. 95, 5949 (2004).

8. National Research Council, End Points for Spent Nuclear Fuel and HighLevel Radioactive Waste in Russia and the United States (The National Academies Press, Washington, DC, 2003).

9. A. Abdelouas, Elements 2, 335 (2006).

10. K. Hart, in Energy, Waste and the Environment: A Geochemical Perspective, R. Gieré, P. Stille, Eds. (Geological Society, London, 2004), p. 25.

11. A. Hedin (SKB Technical Report 97-13, Swedish Nuclear Fuel and Waste Management Co., Stockholm, 1997).

12. A.M. Macfarlane, R.C. Ewing, Eds., Uncertainty Underground-Yucca Mountain and the Nation's High-Level Nuclear Waste (The MIT Press, Cambridge, MA, 2006).

13. R.C. Ewing, in Energy, Waste and the Environment: A Geochemical Perspective, R. Gieré, P. Stille, Eds. (Geological Society, London, 2004), p. 7.

\title{
Preventing Nuclear Weapon Proliferation as Nuclear Power Expands
}

\author{
Siegfried S. Hecker (Stanford University, USA)
}

Raj et al. ${ }^{1}$ describe the promise of nuclear energy as a sustainable, affordable, and carbon-free source available this century on a scale that can help meet the world's growing need for energy and help slow the pace of global climate change. However, the factor of millions gain in energy release from nuclear fission compared to all conventional energy sources that tap the energy of electrons (Figure 1) has also been used to create explosives of unprecedented lethality and, hence, poses a serious challenge to the expansion of nuclear energy worldwide. Although the end of the cold war has eliminated the threat of annihilating humanity, the likelihood of a devastating nuclear attack has increased as more nations, subnational groups, and terrorists seek to acquire nuclear weapons.

The development of commercial nuclear power has had to cope with the specter of potentially aiding the spread of nuclear weapons for its 50 years of existence. Although commercial nuclear power plants have not directly led to weapons proliferation, the technology and infrastructure for commercial and research reactor fuel cycles permit countries to come perilously close to obtaining the fissile materials, ${ }^{235} \mathrm{U}$ or ${ }^{239} \mathrm{Pu}$, that fuel nuclear weapons. The challenge for expanding nuclear power worldwide is to limit the incremental proliferation risk that such expansion presents. The two

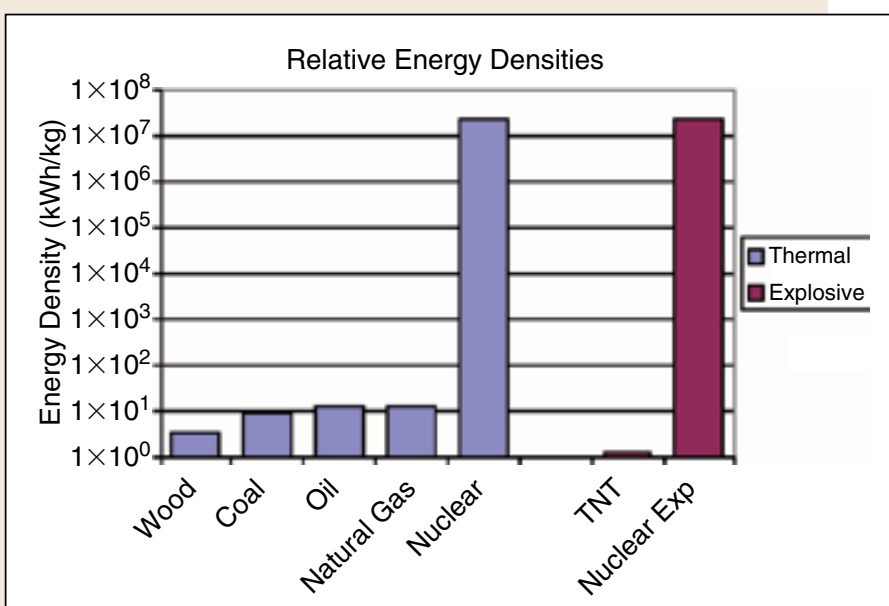

Figure 1. Relative energy densities for nuclear fission compared to conventional energy sources. 
greatest risks are (1) the possibility of fissile materials getting into the hands of subnational groups and terrorists and (2) the potential for breakout and nuclear weapons production as more countries develop fuel-cycle capabilities.

The presidents of the G- 8 industrialized countries have called nuclear terrorism the greatest threat facing civilization today. ${ }^{2}$ It takes less than $10 \mathrm{~kg}$ of ${ }^{239} \mathrm{Pu}$ or a few tens of kilograms of ${ }^{235} \mathrm{U}$ to make a bomb that could destroy a modern city. The ability to produce these fissile materials is beyond the means of terrorist organizations today. However, nearly two million kilograms of each fissile material exist today, making theft or diversion of these materials combined with the construction of an improvised nuclear explosive the most likely route to nuclear terrorism. ${ }^{3}$

This danger exists without an expansion of nuclear power and, in fact, exists even if all nuclear power plants were shut down tomorrow. Much of the inventory of fissile materials, including the most vulnerable stocks, result from military programs of states with nuclear weapons or from civilian nuclear research programs. However, the risk will increase if worldwide expansion of nuclear power brings fuel-cycle capabilities to states that are politically or technically unprepared to safeguard plutonium and highly-enriched uranium (HEU, defined as uranium with $>20 \%{ }^{235} \mathrm{U}$ ). Protecting the world's inventories of fissile materials from terrorists is a monumental job. ${ }^{3}$ It is imperative to address the societal and political dimensions of international terrorism in concert with technical measures to prevent it.

Concern over the proliferation of nuclear weapons to states has also increased as nuclear technologies have spread throughout the world and as the post-cold war security environment leaves more states feeling threatened. Mohamed ElBaradei, Director General of the International Atomic Energy Agency (IAEA), recently stated, "Every country, irrespective of its ideology or worldview, will do what it takes to feel secure, including if necessary seeking to acquire nuclear weapons. This is, sadly, the stark reality...And with more countries acquiring such weapons, the odds of use of such a weapon - either intentionally or accidentally - become higher." ${ }^{\text {4 Developing nuclear }}$ power, especially fuel-cycle capabilities, allows countries to develop a nuclear-weapon option. In fact, the Nuclear Nonproliferation Treaty (NPT) recognizes every state's inalienable right to develop peaceful nuclear energy and applications and even provides for assistance to such states.

On the front end of the fuel cycle (fuel fabrication), enrichment presents the greatest risk. Developing the capabilities to enrich natural uranium from $0.7 \%{ }^{235} \mathrm{U}$ to the $3-5 \%$ required for light water reactors (LWRs), the commercial reactors of choice today, allows for potential clandestine enrichment to bombgrade HEU. That is the essence of the current nuclear controversy in Iran.

On the back end, extracting fissile plutonium represents the proliferation risk. Although LWRs, which burn low-enriched uranium for commercial power, yield a less attractive mix of plutonium isotopes, it is now generally agreed that such plutonium can be used to construct a bomb. ${ }^{5}$ In addition, some reactors use natural uranium, which, if used for very short burn cycles, as was the case for North Korea's 5 MWe (megawatt electric) Experimental Reactor, can yield weapons-usable plutonium. That is the North Korean problem. North Korea turned peaceful technical assistance from the Soviet Union in the 1950s and 1960s into an indigenous nuclear research and power program, built all requisite fuel-cycle facilities, withdrew from the NPT (per Article X), and built a nuclear arsenal. ${ }^{6}$

As more countries develop nuclear power and more fissile materials are created, it is imperative to provide adequate safe- guards of such materials through a combination of technical, institutional, and political measures. These include the following options.

The number of countries that operate front- and back-end fuel-cycle facilities (enrichment and reprocessing, respectively) should be limited. There are currently several international proposals for fuel leasing and fuel take-back services. However, as the Iranian standoff demonstrates, some nations might insist on being self-sufficient. Monitored, retrievable international spentfuel storage is also being considered to deal with back-end fuelcycle concerns.

Another safeguard is international cooperation to increase transparency and enforce the NPT regime. To accomplish this, all countries with nuclear power and research programs must provide greater transparency of operations. All countries must agree to augment the standard IAEA inspections that verify the correctness of a country's declaration with the Additional Protocol that verifies the completeness of their declaration. Moreover, IAEA findings of violations must be backed up by strict enforcement by the United Nations Security Council.

Greater proliferation resistance should be built into the fuel cycle. The technical community has pursued proliferationresistant reactors and fuel cycles for decades, but it is now generally acknowledged that none are proliferation proof. ${ }^{7}$ Several countries have operated a closed cycle with plutonium reprocessing and burning. The United States has practiced an open, once-through cycle with plans for disposition of plutonium with unburned uranium and fission products at Yucca Mountain, NV. As part of its Global Nuclear Energy Partnership, it is now exploring various closed-cycle options and reactor designs, including fast reactors, that provide improved proliferation resistance through actinide recycling to limit the amount of direct-use plutonium. The materials challenges for such a scheme are embedded in the challenges faced by the development of advanced fuels and reprocessing operations. ${ }^{1}$

Another safeguard would be to develop better detection and monitoring capabilities. All fuel cycles require safeguarding fissile materials, which, in turn, requires better detection and monitoring technologies. Research on better detector materials plays an important role in developing more effective means to detect neutrons and gamma rays. Materials research is also needed to develop better environmental monitoring capabilities to look for clandestine nuclear processing activities. Likewise, establishing a databank of nuclear materials "fingerprints" would aid nuclear forensics and attribution. ${ }^{8}$

Nuclear power and fuel-cycle facilities must be protected from sabotage and terrorist attacks. Although attacks on nuclear plants or facilities will not cause nuclear detonations, the spread of radioactivity could cause serious harm and enormous disruption. If more nuclear power plants and facilities come on line, it will be important that all be well protected against potential terrorist attacks. The incremental risk of expanding nuclear power on the potential of radiological terrorism (the radiological dispersal device or "dirty bomb" threat) is judged to be small because millions of radiation sources that could fuel such devices already exist in medicine, agriculture, and industry.

A large expansion of nuclear power in this century may meet the challenge of affordable, sustainable energy while slowing global climate change. To achieve this end, however, we must minimize the risk that such an expansion will lead to the proliferation of nuclear weapons. This challenge can be managed through the proper combination of technical, institutional, and political measures. 

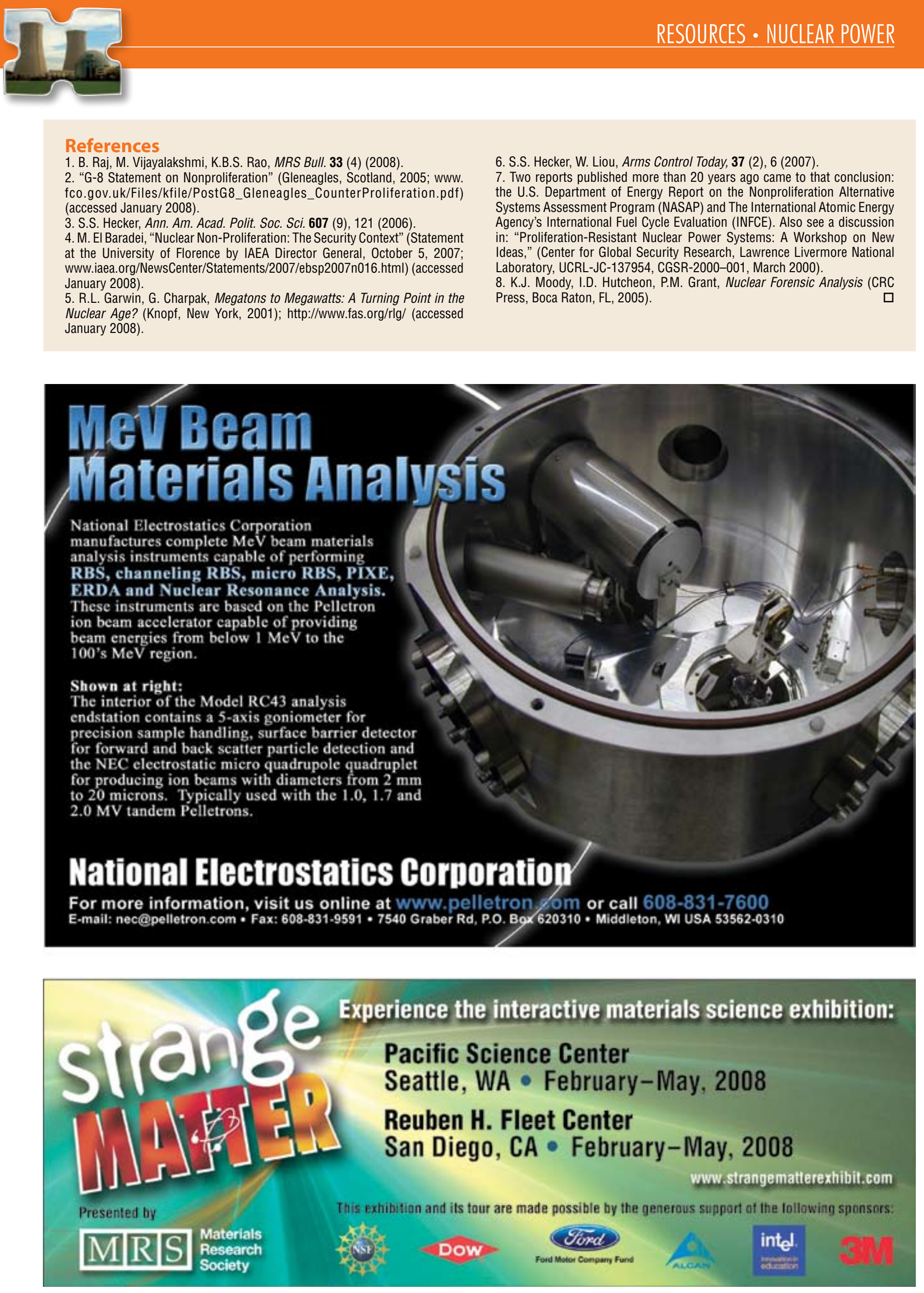

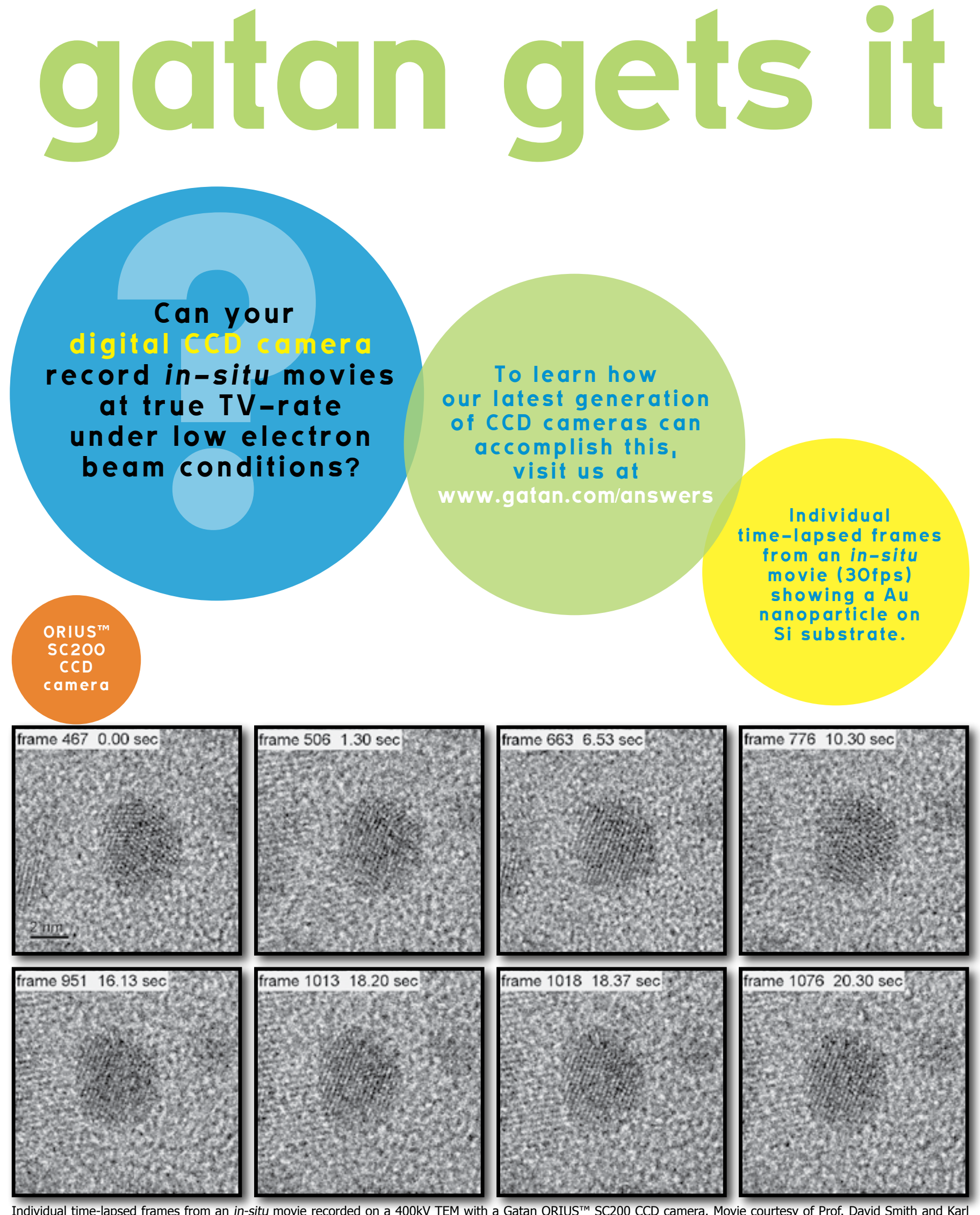

Weiss, Center for Solid State Science (CSSS), Arizona State University.

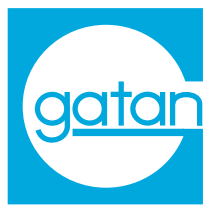

